\title{
IMPACT OF AUTOMOTIVE AND MOTORCYCLE SPORT ON THE ENVIRONMENT
}

\author{
B. Doytchev* \\ Department of Sports Medicine, Sector Ecology, National Sports Academy \\ "Vassil Levski", Sofia, Bulgaria
}

\begin{abstract}
Automotive and motorcycle sports are motor sports in which various vehicles (serial and modified cars, motorcycles, buggies, jeeps, trucks, prototypes, etc.) compete with engines of different types (electric motors, hybrid and mostly thermal internal combustion engines - piston and partly rotary). Interest in the discuss sport are progressively increases in the years from people of different age groups. The article comments on environmental issues related to these sports and environmental recommendations for their application. The combined efforts of various institutions are needed to increase the popularity and awareness of sport that can be realized under optimal environmental conditions and does not impair its environmental sustainability. This requires an actual environmental policy and education aimed at future development in this direction.
\end{abstract}

Key words: automotive and motorcycle sport, ecology, pollution, environment.

Automotive and motorcycle sports are motorsports in which various vehicles (serial and modified cars, motorcycles, buggies, jeeps, trucks, prototypes, etc.) compete with engines of different types (electric motors, hybrid and mostly thermal internal combustion engines piston and partly rotary). Interest in the sport at issue is progressively increasing throughout the years, encompassing people of different age groups. This article tackles the environmental issues related to these sports and the environmental recommendations for their application. The combined efforts of various institutions are needed in order to increase the popularity and awareness of a sport that can be realized under optimal environmental conditions and does not impair its environmental sustainability. This requires an up to date environmental policy and education aimed at future development in this direction.

Automotive and motorcycle sports are motorsports in which various vehicles (serial

\footnotetext{
*Correspondence to: Chief Assist. Assoc Boyan Doychev, Ph.D. - NSA, Department of Sports Medicine,Sector Ecology, 1700 Sofia, Studentski Grad
}

and modified cars, motorcycles, buggies, jeeps, trucks, prototypes, etc.) compete with engines of different types (electric motors, hybrid and mostly thermal internal combustion engines piston and partly rotary). It's one of the most popular sports. Some of the best-known competitions today include Formula 1, Formula E, NASCAR, IndyCar, Dakar Rally, World Rally Championship, Gran Turismo races, cross-country rallying performed on different types of terrain. This article tackles the environmental issues related to these sports and the environmental recommendations for their application.

\section{Automobile and motorcycle sport}

Races, slaloms, meetings, and master driving tests are conveyed on certain types of surfaces, such as race tracks, test tracks, parking lots, open roads, pavement, macadam and dirt roads, deserts, mountain roads, etc. There are different types of races, such as driving through mountain terrains; cross-county master driving, navigating through hard terrain, while meetings are conveyed on open roads and highways. Mountain climbing competitions, cross country rallies, "Baja" Rally, Marathon Rally, Rally Sprint, autocross, and trials are conveyed in the "open": mountain passes, 
DOYTCHEV B.

gravel, sand, arable and agricultural land and so on.

Track races and master driving competitions are conveyed on certain types of surfaces, such as race tracks, test tracks, stadiums or enclosed sports facilities.

Road races, descents as well as a different type of motorsport competitions, including tests (such as participants commencing at different starting points) are conveyed on public roads and parking lots.

Endurance motocross and cross country motorcycle competitions are conveyed in the "open" (dirt roads).

Sports driving is not racing - it is fast but as safe as possible, with a reserve of traction, braking distance, power, etc. The car is not used as a means of transport from point $A$ to point $\mathrm{B}$ but as a racing machine. Sports driving is practiced only in safe areas. It can be transferred on open roads, but after achieving the necessary driving techniques on closed tracks. The core of sport driving is safety. The idea to preserve ourselves and others on the road, to anticipate actions and last, but not least - with the necessary dose of self-confidence. [3]

Driving improvement lessons should be conveyed on safe, enclosed tracks. On such tracks, the drivers can acquire the skills that can help them to be safer on the road. The training is a prerequisite for acquiring the socalled. "Sporty Driving" - a combination of fast and safe driving. [3]

In addition to their harmful effects on the environment, motorsports are fraught with contradictions for environmentalists, as they encourage the use of motorized forms of transport (not only for racing purposes) and thus indirectly contribute to the high levels of stress, associated with driving (piloting) in a natural environment. [9]

The main conflicts, between these sports and the requirements for nature preservation and eco-environment, fall into the following categories: contamination of the physical environment (from emissions of exhaust gases or through the noise (sound intensity) or deterioration of ecosystems (from driving on paved roads in environmentally sensitive areas).
One of the main sources of air pollution is road transport, which is also the most widespread in the world as a massive means of transport. There has been a marked increase in the number of vehicles over the last two decades. From it, we can exclude vehicles powered by electricity and hydrogen. At this stage of development, their share is very small, but with great tendencies for future development.

The amount of exhaust emissions emitted depends on the type of engine, its power, year of production, technical condition, availability of catalyst converter, fuel quality, mileage, traffic.

Transport is a significant source of air pollution in the cities in Bulgaria, which is due to a number of factors: increasing the number of cars (especially of old cars imported after 1990), the long life of the vehicle (over 10-20 years), bad technical condition of many of them; the use of two-stroke cars (about $5 \%$ of the total). Vehicles used for transport emit carbon, nitrogen and sulfur oxide, carbon dioxide and nitrogen dioxide, fine particulate matter, hydrocarbons, lead and various unidentified atmospheric pollutants [1].

Noise pollution (acoustic) can also be a detrimental environmental factor. Mechanical vibrations of environmental particles (air, water, etc.) are propagated in the form of waves, called noise (sound intensity). Under noise, it's implied the uncharacteristically mixed sounds of different frequencies.

It refers to sounds of different origins and types, perceived by man as irritating and often causing painful sensations. According to the Environmental Protection Act (published in State Gazette 74/2005), it is an undesirable or harmful external factor caused by human activity, incl. noise from vehicles from road, rail, water, air transport and others. Whether a sound will be perceived as irritating depends on both its physical characteristics and its subjective attitude towards it.

To the nature of background noise, in modern living conditions are added various industrial, transport, agricultural and other noises. Environmental noise caused by industrial, construction, transport and repair activities is one of the main environmental problems in urbanized areas. For our country contributes the outdated fleet and the poor state of the Republican road network. Strong noise can force certain species of animals to change their 
habitats and distort environmental conditions [1].

The German Technical Monitoring Association (Technischer über-Wachungsverein Norddeutschland) and other institutions (quoted in UBA 1989) recorded the emission value for noise (acoustic integration) in motor sports facilities as follows:

Motocross: $128 \mathrm{db}$ (a) when motorcycles are in operation in $70 \%$ of the total time of the sporting event.

Speed races: $135-138 \mathrm{db}$ (a) when motorcycles are in operation during $40 \%$ of an event.

Sand Track: $137 \mathrm{db}$ (a) when motorcycles are in operation during $40 \%$ of an event [5].

In all types of competitions the noise is controlled. The noise level produced by a rally motorcycle horn is over $97 \mathrm{db}$ [2].

The use of nearby natural areas (such as forest, farmland, abandoned and low-intensity grassland) for motorsports is serious environmental stress and worsens the state of ecosystems by eradicating vegetation, soil compaction, stressing valuable animals or relocating them from the affected area. Not only sporting events can lead to serious damage to sensitive terrain but also training and increasingly occasional recreational activities of motorcycle owners [9].

Motorcycle clubs and organizations can control, stop undisciplined environmental reckless off-road driving, urging their members to practice motorsport only on surfaces that are officially designed for them.

The following three types of motorsports are the most common in open areas:

- Motocross, in which the contestants accelerate the speed massively along the circular route without an endpoint, leading to bruises in the ground.

- Endurance cross-country motor racing competitions that take place on paved roads, unpaved agricultural and forest roads, and off-road on various types of terrain.

- Master driving tests that test only racing skills and agility.

Preventive measures for motor vehicles against air pollution, noise, reduced fuel consumption and reduction of the waste are:

- Reduce emissions (use of unleaded petrol);
- Regular technical inspections are carried out and the advice on proper maintenance of motor vehicles is respected;

- To reduce noise by alternative methods, planning, and production of motor vehicles and parts that work more quietly;

- Reduce fuel consumption (energy saving);

- To stimulate the production of motor vehicles and motorcycles parts that last long enough (reduction in waste generation);

- Use products or parts made of recycled materials for making new ones;

- To collect separately discarded tires, accumulators, oils and liquids.

\section{o Appropriate areas for motocross, cross- country and Master driving.}

Suitable areas are terrains that can offer the necessary challenges peculiar to cross-country races and have an increased level of difficulty. Another requirement is not to have habitats with ecologically valuable and sensitive areas, rich biodiversity, dry grassland, wetlands, coastal dunes and ecologically sensitive forest funds, which are particularly problematic [4].

\section{The following areas meet these conditions:}

- Sandy, rocky and stone areas, paved roads, unpaved agricultural and forest roads. If necessary, artificial obstacles can be built to test racing skills and agility.

- Abandoned warehouses and industrial areas, as well as open areas for automotive waste. They often contain conditions suitable for motorsports or can offer good opportunities for conversion. Military bases and abandoned airports, which in some cases for certain periods of time, open doors for the enthusiasts of motor sports. They can be carried out in areas of bases, commonly used for military equipment testing, tuning, and counteraction.

- Sports arenas and stadiums. These buildings can provide opportunities for cross-country racing.

All parts of the landscape, close to its natural state (such as dry grassland, wetlands, coastal dunes and ecologically sensitive forest funds) should be closed off for motorsport activities. Proper maintenance and good technical condition of motor vehicles are essential, which will prevent oil and cooling fluids from leaking to the ground and thus prevent potential danger to the terrestrial, subsoil and adjacent aquatic ecosystems. [8] 
- Additional recommendations

and appropriate behavior:

- To participate only in appropriately organized events that have the necessary permits;

- To reduce pollutant emissions;

- Reduce fuel consumption;

- To reduce the use of petrol and, as far as possible, to use unleaded fuel;

- Follow the advice on proper maintenance of motor vehicles;

- Avoid the increase of noise that would irritate others;

- Use environmentally friendly vehicles;

- Repair of engines (as a result of accidents) should be conducted only on asphalt or concrete surfaces which have a protective coating of the soil;

- Clean and remove all forms of soil contamination resulting from accidents and spills;

- Avoid damage to soil, plants and the environment;

- Avoid causing tracks or holes in the soil;

- Dispose of tires, motor oil and coolant separately from other wastes;

- Avoid participating in competitions that do not have the necessary permits;

- Don't ever drive in areas not specifically designated for automotive sports;

- Do not rev the engine during the ceremonial start-finish;

- Do not perform burnouts during the ceremonial start-finish;

- Do not open the car race cover during the race and perform repairs during the "Parc ferme" regime;

- Don't clean vehicles outdoors and use only biodegradable substances;

- Do not discard or leave waste in order that will pollute soil, groundwater, and adjacent water sources;

- Never dispose of waste, such as tires, batteries, engine oil, coolant, gasoline or diesel in the environment (punishable offense).

An example of environmental policy is the National Commission on Motor Racing in Germany (ONS). It has designated mandatory exhaust and noise emission rules. As from January 1, 1997, they are obligatory for all automotive racing events approved by the Commission, leading to a reduction in the amount of noise and emissions produced in races (ONS 1997). [7].

The International Motor Sport Committee has published a comprehensive "environmental code" that provides regulation and recommendations for motorcycle sports. The aim of the code is "to
DOYTCHEV B.

share the interaction between motorcycling and environmental requirements positively". The regulations and recommendations focus in particular on:

- Problems related to noise, fuel, soil protection and cleaning of vehicles and equipment;

- Viewers' behavior, event organizers, traffic managers and motorcyclists sharing traffic lanes with other motorists.

The Code is an application that contains checklists for various motorsport disciplines as well as tourist motorcycling (OMK 1997) [6]

\section{CONCLUSION}

Interest in the sport at issue is progressively increasing in the years, encompassing people of different age groups. The combined efforts of various institutions are needed to increase the popularity and awareness of sport that can be realized under optimum environmental conditions and does not impair its environmental sustainability. This necessitates an up-to-date environmental policy and education aimed at future development in this direction.

\section{REFERENCES}

1. Doytchev, B. Ecology, pub. "Vanguard Prima ", S., 2018.

2. Iliev, V., D. Iliev Motoring, NSA Press, S., 2010

3. Iliev, D., D. Peshev Steering Wheel, Bolid ins, S., 2015.

4. ADAC Sport: Environmental Plan 2000+, Environmentally friendly motorsport on the way to the 21st century. Munich (2nd edition) 1997.

5. BAUER, $\mathrm{H}$ : Motorsport and the environment - presentation of a problematic relationship with special consideration of possible solutions, European university publications Peter Lang 1989.

6. OMK (Supreme Motorcycle Sports Commission), ed.: Environmental Code of the FIM, Frankfurt 1997.

7. Ons (Supreme National Sports Commission for Automobile Sports in Germany): Automotive sport: Getting started easy! 2. Frankfurt 1993.

8. Schemel, H.J.: Environmentally Compatible Leisure Facilities - A Guide to the Testing of Ski, Water and Golf Sports Projects from the Environmental Perspective, Vol. 1 (Analysis and Assessment), Reports by the Federal Environmental Agency, Vol. 5, 1987.

9. SCHULTHEISS, H .: Motocross: Dangers for nature and landscape. In: ABN (ed.) Sport and nature conservation in conflict a.a.O., 1986. 